\title{
History of dating violence and the association with late adolescent health
}

\author{
Amy E Bonomi ${ }^{1,2,3^{*}}$, Melissa L Anderson ${ }^{3}$, Julianna Nemeth ${ }^{4}$, Frederick P Rivara ${ }^{5,6}$ and Cynthia Buettner ${ }^{1}$
}

\begin{abstract}
Background: The present investigation expands upon prior studies by examining the relationship between health in late adolescence and the experience of physical/sexual and non-physical dating violence victimization, including dating violence types that are relevant to today's adolescents (e.g., harassment via email and text messaging). We examined the relationship between physical/sexual and non-physical dating violence victimization from age 13 to 19 and health in late adolescence/early adulthood.
\end{abstract}

Methods: The sample comprised 585 subjects (ages 18 to 21; mean age, 19.8, SD $=1.0$ ) recruited from The Ohio State University who completed an online survey to assess: 1) current health (depression, disordered eating, binge drinking, smoking, and frequent sexual behavior); and 2) dating violence victimization from age 13 to 19 (retrospectively assessed using eight questions covering physical, sexual, and non-physical abuse, including technology-related abuse involving stalking/harassment via text messaging and email). Multivariable models compared health indicators in never-exposed subjects to those exposed to physical/sexual or non-physical dating violence only. The multivariable models were adjusted for age and other non-dating abuse victimization (bullying; punched, kicked, choked by a parent/guardian; touched in a sexual place, forced to touch someone sexually).

Results: In adjusted analyses, compared to non-exposed females, females with physical/sexual dating violence victimization were at increased risk of smoking (prevalence ratio $=3.95$ ); depressive symptoms (down/hopeless, $P R=2.00$; lost interest, $P R=1.79$ ); eating disorders (using diet aids, $P R=1.98$; fasting, $P R=4.71$; vomiting to lose weight, $P R=4.33$ ); and frequent sexual behavior ( $5+$ intercourse and oral sex partners, $P R=2.49, P R=2.02$; having anal sex, $P R=2.82$ ). Compared to non-exposed females, females with non-physical dating violence only were at increased risk of smoking $(P R=3.61)$, depressive symptoms (down/hopeless, $P R=1.41$; lost interest, $P R=1.36$ ), eating disorders (fasting, $P R=3.37$; vomiting, $P R=2.66$ ), having $5+$ intercourse partners $(P R=2.20$ ), and having anal sex $(P R=2.18)$. For males, no health differences were observed for those experiencing physical/sexual dating violence compared to those who did not. Compared to non-exposed males, males with non-physical dating violence only were at increased risk of smoking $(P R=3.91)$ and disordered eating (fasting, using diet aids, vomiting, $\mathrm{PR}=2.93$ ).

Conclusions: For females, more pronounced adverse health was observed for those exposed to physical/sexual versus non-physical dating violence. For both females and males, non-physical dating violence victimization contributed to poor health.

Keywords: Adolescents, Adolescent sexual behavior, Dating violence, Depression, Eating disorders

\footnotetext{
* Correspondence: bonomi@msu.edu

'Human Development and Family Science, The Ohio State University,

Columbus, OH, USA

${ }^{2}$ Human Development and Family Studies, Michigan State University, East

Lansing, MI, USA

Full list of author information is available at the end of the article
}

\section{Biomed Central}

(c) 2013 Bonomi et al.; licensee BioMed Central Ltd. This is an Open Access article distributed under the terms of the Creative Commons Attribution License (http://creativecommons.org/licenses/by/2.0), which permits unrestricted use, distribution, and reproduction in any medium, provided the original work is properly cited. 


\section{Background}

Approximately 36 percent of males and 44 to 88 percent of females experience dating violence victimization across the adolescent/young adult period [1,2]. Among females, studies have shown an association between having a history of physical and/or sexual dating violence victimization and poor health during adolescence-including depression [3-5]; anxiety and stress symptoms [6]; suicide ideation and/or attempts [5,7-11]; smoking, alcohol and drug use $[3,5,8,10]$; disordered eating (e.g., using laxatives and/or vomiting to lose weight) $[8,10,11]$; contracting a sexually transmitted disease [12,13]; having multiple sex partners [14]; pregnancy [8,14]; and diminished quality of life [7]. Male victims of physical and/or sexual dating violence during adolescence are at increased risk of disordered eating [4,5]; anxiety, stress symptoms and depression [4-6]; suicidal ideation and/or attempts [4,5]; smoking, alcohol and drug use [4,5,10]; and diminished emotional well-being [11]. Both physical and emotional types of dating violence increase anxiety and depression in adolescent males and females [15].

A recent longitudinal study by Exner-Cortens and colleagues (2013) examined health in late adolescence/young adulthood by dating violence types (psychological violence only and physical and psychological violence together) experienced from age 12 to 18 [16]. Subjects who experienced both physical and psychological violence were at risk for poor health outcomes; exposed females had increased risk of depression symptoms, suicidal ideation, smoking, and adult violence victimization, and exposed males had increased risk of adult violence victimization. Females who experienced psychological violence only were also at increased risk of heavy episodic drinking and adult violence victimization, and exposed males were at risk of antisocial behaviors, suicidal ideation, marijuana use, and adult violence victimization. The findings from Exner-Cortens' study support those from other studies showing an increased risk of violence re-victimization in late adolescence/young adulthood if experienced earlier in adolescence $[1,2,17]$.

Despite the strengths of the Exner-Cortens' study (longitudinal design, large sample affording a separate assessment of how violence types impacted health outcomes) [16], the violence assessment was limited. Namely, violence victimization was assessed using five questions (called names/insulted; sworn at; threatened with violence; pushed/shoved; and had something thrown that could hurt). The assessment did not cover the range of violence types (physical, sexual, and nonphysical abuse) recommended for assessment by the U.S. Centers for Disease Control and Prevention [18-20], including violence types relevant to today's adolescents, such as harassment/stalking via text messaging, email, and social media [21,22].
Studies of adults have more extensively parsed health effects by specific types of violence experienced in intimate relationships, including a consideration of the different violence types (physical, sexual, and non-physical abuse) recommended for assessment by the U.S. Centers for Disease Control and Prevention [18-20]. These studies have shown that adults who experience physical/ sexual types of violence within intimate (e.g., dating, marital) relationships tend to have more pronounced adverse health impacts (e.g., depression, chronic disease) than adults who experience non-physical types of abuse only (e.g., controlling behavior, insults) [23-26]. Sexual violence has the most devastating impacts on the health of adult women, including an association with severe depressive symptoms, post-traumatic stress disorder, anxiety, difficulty sleeping, fair/poor health, physical/ somatic symptoms, cigarette smoking, and problem drinking [25,27]. However, the experience of nonphysical victimization only (in the absence of physical/ sexual abuse) is also associated with adverse mental health in adult women and men [23-26]. For example, in Bonomi's study of 3,429 women ages 18 to 64, women who experienced recent non-physical intimate partner violence only had significantly lower vitality and social functioning, and were more likely to have minor or severe depressive symptoms compared to non-abused women [24].

The present investigation expands upon prior studies by examining the relationship between health in late adolescence and the experience of physical/sexual and non-physical only (e.g., threats, controlling behavior) dating violence from age 13 to 19 . Our study significantly adds to the literature on the health correlates of specific types of adolescent dating violence. Specifically, our study includes an expanded assessment of how dating violence types relate to health in late adolescence, including dating violence types that are relevant to today's adolescents [22]. Particularly relevant in today's society are the ways in which technology, such as text messaging, email and social media [21,22,28-39], has affected teen relationships, including violence occurring in those relationships. For example, cell phones and other electronic mechanisms provide pathways for increased monitoring and harassment of dating/romantic partners and may exacerbate jealousy [21]. Yet, little is known about how excessive monitoring through mechanisms such as cell phones or email relate to late adolescent health. Similarly, "hooking up," which is a primary pathway to relationship formation among today's adolescents [40], also presents unique challenges $[40,41]$ by presenting a ripe context for unwanted/ coerced sex. Related, our study examines the association between sexual violence through verbal coercion and/or physical force and health in late adolescence [42-44]. 


\section{Methods \\ Sample}

Study procedures were approved by the institutional review board of The Ohio State University, including procedures to ensure the confidentiality and anonymity of subjects' responses (e.g., data were immediately stripped of identifying information). The analytic sample comprised 585 subjects ages 18 to 21 enrolled at The Ohio State University, recruited in two data collection efforts. Subjects completed a one-time only online survey to assess current health and retrospective dating violence histories from age 13 to 19 (described below). The recruitment procedures were as follows:

- Study 1, conducted from March, 2011 to April, 2011, involved randomly sampling 730 students from the registrar's office, from a total of 32,716 students age 18 to 21 enrolled at Ohio State University [22]. Using students' university email account, we sent a recruitment email, which included the study description and link to the online survey. Two follow-up reminders were sent by email, three and seven days after the initial email. The cumulative response rate at each recruitment email was as follows: initial email (31.6\%, 231/730); second email (41.0\%, 300/730); final email $(46.7 \%, 341 / 730)$ [22]. Subjects who completed the survey were credited $\$ 20$ to their university account. Of the 341 subjects who completed the survey, 44 were excluded because they were older than age $21(n=7)$ or because they never had a dating partner from age 13 to $19(\mathrm{n}=37)$. After these exclusions, the eligible analytic sample comprised 297 subjects who had a dating partner from age 13 to $19(\mathrm{n}=190$ females; $\mathrm{n}=107$ males).

- Study 2, conducted from May, 2011 to March, 2012, involved recruiting students ages 18 to 21 enrolled in four undergraduate Human Development and Family Science courses at The Ohio State University. Through an introductory email which included the study description and survey link, instructors offered completing the survey as extra credit coinciding with the coverage of relationshiprelated topics in class. A total of 311 students completed the survey; according to the class rosters, this represented $98 \%$ of eligible students. Of the 311 students, the eligible analytic sample comprised 288 subjects who had a dating partner from age 13 to 19 ( $\mathrm{n}=255$ females and 33 males). The overdistribution of females in the sample is consistent with the gender distribution in the Human Development and Family Science undergraduate program.
- Our current analysis combined the two samples, totaling 585 subjects $(\mathrm{n}=297$ from the first study plus 288 from the second study). The overdistribution of females in Study 2 (recruited from undergraduate classes) compared to Study 1 (recruited through the university registrar) represented the main difference between the two samples, with otherwise similar characteristics between the two samples due to our narrow eligibility criteria (e.g., subjects had to be between the ages of 18 and 21).

\section{Survey}

\section{Health and health behaviors}

To reduce response bias, subjects were first asked about health before they were asked about dating violence victimization. Asking subjects details about dating violence first, which could be a traumatic experience, could potentially cause bias in their responses to the health items; specifically, subjects might provide lower health ratings if the experience of completing the dating violence questions was traumatic [24].

- Depressive symptoms over the last two weeks were assessed using two questions from the nineitem Patient Health Questionnaire [45], which have a sensitivity of $74 \%$ for detecting depressive symptoms among adolescents relative to the Diagnostic and Statistical Manual of Mental Disorders [46]. The two questions included:

$\circ$ Having little interest in doing things;

- Feeling down/hopeless.

- The two depression questions were scored as separate items, not as a composite measure; the response options for each question ranged from 0 (not at all) to 3 (nearly every day). In the analysis, the item responses were collapsed into a binary category $(0=$ not at all; $1=$ experienced symptoms on any day).

- Unhealthy/disordered eating behaviors were assessed using three questions from the Youth Risk Behavior Surveillance System [47], including whether subjects ever:

- Fasted, vomited, or took diet aids to lose weight (each its own separate question).

- Response options to the questions were binary (yes/ no).

- Binge drinking and smoking were assessed using questions from the Youth Risk Behavior Surveillance System [47], including:

- Ever smoked daily for 30 or more days;

- Had 5 or more drinks on six or more days over last month. 
- Response options to the questions were binary (yes/no).

- Sexual behavior was assessed by asking about subjects' ever engagement (yes/no) in vaginal/penile intercourse, oral sex, and anal sex, and the number of partners they engaged in the sexual activity with (subjects reported the number of partners). The cut point for frequent oral and vaginal sex was defined as having five or more partners. Anal sex was less common, so the definition included having had any anal sex. While these measures are likely to indicate sexual health risk from sexual transmitted infections and unwanted pregnancy, they may not constitute equivalent risk.

\section{Relationship and dating violence histories}

We used a method similar to the timeline follow-back interview to assess dating violence histories retrospectively from age 13 to 19 [48-50]. We previously used this method to document domestic violence and child abuse histories in more than 4,000 women and men [24-26,51-57]. While retrospective dating violence assessment may result in mis-estimation of abuse due to recall bias [58,59], retrospective assessment is the field's standard for capturing adolescent dating violence experiences and our assessment method used memory prompts to facilitate recall. The timeline follow-back interview method has been used extensively to capture other risky health behaviors, such as drug and alcohol use [48-50]. First, to establish relationship histories, subjects were asked whether they had a dating, romantic or sexual partner between age 13 and 19; this could include a boyfriend/girlfriend, someone the subject liked romantically or was involved with sexually but did not consider to be a boyfriend or girlfriend, or someone the subjected "hooked up with" [22]. They were then asked specific details about their three most recent partners, starting with their most recent partner, including the partner's gender, the age the relationship began and ended, and the partnership type (e.g., boyfriend/girlfriend) [22,60]. We used memory prompts, such as asking the subject to remember the year they were in high school, to facilitate recall of the age that a relationship began and ended. For operational practicality, we asked details about subjects' three most recent partners [22]. After we asked subjects detailed questions about their three most recent partners, we asked about the total number of partners subjects had beyond those three from age 13 to 19 .

After information about subjects' relationship history was gathered, dating violence victimization was assessed retrospectively using eight questions covering the three core conceptual areas of intimate (including dating) violence (physical, sexual, and non-physical) outlined by the Centers for Disease Control and Prevention [18-20] (Table 1):

Our eight questions were adapted from the CDC's Youth Risk Behavior Surveillance System [47], Foshee and Swahn's studies [61-63], and Coker's dating violence survey currently being administered in a CDC-funded intervention study (unpublished data, personal communication with Dr. Coker). Additionally, our questions included newer forms of dating violence/abuse, including harassment/stalking through text messaging and email. Initial validity data from the eight dating violence questions we used in the present study were presented at the Women's Health Congress in Washington, D.C. in March 2013 [64], and the validation manuscript is undergoing peer review; in brief, a confirmatory factor analysis of the eight dating violence questions showed that the questions loaded onto the hypothesized conceptual abuse factors (physical, sexual and non-physical abuse) [65].

For each question in Table 1, subjects were asked whether they ever experienced dating violence between age 13 and 19. Subjects who responded with "yes" were considered exposed to that abuse type. We created the following exposure groups based on prior studies that have conceptually and empirically examined physical and sexual violence within a single category $[23,24,27,66]$, and psychological abuse only in a separate category $[16,23,24,67]$.

Table 1 Dating violence questions (Has any partner you've been involved with between ages 13 and 19 ever ...)

\section{Physical/}

sexual

...hit, slapped, or physically hurt you on purpose?

pressured you to participate in sexual activities by begging or arguing with you, or by threatening to end your relationship?

. pressured you to participate in sexual activities by threatening you with physical force (i.e., twisting your arm or holding you down)?

Non-physical

.threatened to hit or slap you, to spread rumors about you, to destroy something belonging to you, or to harm you in some other way?

...tried to control your behavior by always checking up on you, telling you who your friends could be, or telling you what you could do and when?

..called you names, put down your looks, or said things to hurt your feelings on purpose?

shouted, yelled, insulted, or sworn at you?

..made unwanted phone calls, send unwanted text messages, emails, or gifts, or showed up in person and waited for you when you didn't want them to? 
- Physical and/or sexual dating violence exposure included subjects who reported experiencing physical and/or sexual types of dating violence. Subjects in this group could also have exposure to non-physical abuse. We included exposure to sexual pressure involving either (or both) verbal and physical coercion, as verbally coerced sexual acts have been shown to have lasting trauma for victims [25,43].

- Non-physical only dating violence exposure included subjects who were not exposed to physical/sexual dating violence, but who reported experiencing any of the non-physical dating violence types listed in Table 1. For ease in reporting, this group is referred to as the "nonphysical TDV" group.

- Non-exposed subjects included those who reported never experiencing physical, sexual, or non-physical types of dating violence from age 13 to 19 .

\section{Other (non-dating) abuse exposures}

Using three questions from the Centers for Disease Control $[47,68]$, we asked about 1$)$ whether subjects had ever been bullied between ages 13 and 19 (1 question); and 2) whether subjects experienced other types of abuse before age 18, including being punched, kicked, choked, or receiving a more serious physical punishment from a parent or other adult guardian (1 question) and being touched in a sexual place or being forced to touch another person when they did not want to (1 question).

\section{Analysis}

All analyses were gender stratified. Chi-square tests were used to compare health indicators for subjects who reported any dating violence victimization with those who reported no victimization. Generalized linear models with a log link and robust sandwich variance estimators were used to obtain prevalence ratios (PRs) for each dichotomous health indicator for exposed compared to unexposed subjects, using a modified Possion regression approach [69]. Logistic regression models were not used because the health outcomes were not rare, and the odds ratios from these models would not closely approximate relative risks (or equivalently, prevalence ratios). The analyses investigated the effects of the type of dating violence experienced (physical/ sexual versus non-physical only) on health indicators; specifically, regression coefficients compared health indicators in subjects with physical/sexual dating violence exposure compared to never-exposed subjects, and compared those with non-physical only dating violence compared to never-exposed subjects. We fit unadjusted and adjusted models; the adjusted models were adjusted for age, bullying victimization from age 13 to 19 , and other non-dating physical and sexual abuse before age 18 (see Methods section and footnote in Table 2 for definitions)-all of which are theoretically linked and empirically associated with health impairments [58,70-75]. Analyses were completed using Stata statistical software, version 12.0 [76].

\section{Results}

\section{Characteristics of the study sample}

The average age of subjects was 19.8 years, $76 \%$ comprised females, and most were enrolled in their freshmen or sophomore year (Table 2). Consistent with the

\section{Table 2 Characteristics of the study sample}

\begin{tabular}{|c|c|c|}
\hline & Female & Male \\
\hline Total & $N=445$ & $N=140$ \\
\hline Age, mean (SD) & $19.8(1.0)$ & $19.8(1.0)$ \\
\hline \multicolumn{3}{|l|}{ Year in college } \\
\hline Freshman & $114(25.8)$ & $45(32.1)$ \\
\hline Sophomore & $149(33.7)$ & $41(29.3)$ \\
\hline Junior & $139(31.5)$ & $41(29.3)$ \\
\hline Senior & $40(9.1)$ & $13(9.3)$ \\
\hline Missing & 3 & 0 \\
\hline \multicolumn{3}{|l|}{ Race } \\
\hline White & $377(85.1)$ & $116(82.9)$ \\
\hline Black & $26(5.9)$ & $12(8.6)$ \\
\hline Asian & $24(5.4)$ & $11(7.9)$ \\
\hline Other & $16(3.6)$ & $1(0.7)$ \\
\hline Missing & 2 & 0 \\
\hline \multicolumn{3}{|l|}{ Sexual orientation } \\
\hline Heterosexual & $410(92.3)$ & $127(90.7)$ \\
\hline Bisexual & $16(3.6)$ & $1(0.7)$ \\
\hline Homosexual & $6(1.4)$ & $7(5.0)$ \\
\hline Asexual & $12(2.7)$ & $5(3.6)$ \\
\hline Missing & 1 & 0 \\
\hline \multicolumn{3}{|c|}{ Ever been bullied (age 13 to 19) } \\
\hline No & $247(55.9)$ & $78(56.1)$ \\
\hline Yes & $195(44.1)$ & $61(43.9)$ \\
\hline Missing & 3 & 1 \\
\hline \multicolumn{3}{|c|}{ Physical child abuse } \\
\hline No & $410(92.8)$ & $127(91.4)$ \\
\hline Yes & $32(7.2)$ & $12(8.6)$ \\
\hline Missing & 3 & 1 \\
\hline \multicolumn{3}{|c|}{ Sexual child abuse } \\
\hline No & $387(88.0)$ & $135(97.1)$ \\
\hline Yes & $53(12.0)$ & $4(2.9)$ \\
\hline Missing & 5 & 1 \\
\hline
\end{tabular}


Ohio State University student population in general (http://undergrad.osu.edu/admissions/quick-facts.html), most subjects reported that they were White (85\% for females, $83 \%$ for males) and over $90 \%$ were heterosexual. Approximately $44 \%$ of subjects had been bullied between age 13 and 19. The proportion of females and males who suffered non-dating physical abuse before age 18 (being punched, kicked, choked, or receiving a more serious physical punishment from a parent or other adult guardian) was $7.2 \%$ and $8.6 \%$, respectively. The proportion of females and males who were touched in a sexual place or forced to touch another person when they did not want to before age 18 was $12 \%$ and $2.9 \%$, respectively.

\section{Prevalence of dating violence victimization}

Table 3 shows the prevalence of dating violence victimization among females and males. A total of $67.4 \%$ of females and $57.1 \%$ of males reported dating violence victimization from age 13 to 19 .

A total of $28.4 \%$ of females and $19.3 \%$ of males experienced physical and/or sexual violence; sexual violence experienced by females and males was mostly verbally coerced $(25.3 \%, 9.4 \%)$ rather than physically forced (5.4\%, 0.7\%). Non-physical dating violence victimization occurred more frequently than physical/sexual violence, with $64.6 \%$ of females and $56.4 \%$ of males indicating they experienced this type of dating violence. Specific estimates of the various types of non-physical abuse are provided in Table 3; for example, being yelled at, sworn at, or insulted was the most common type of nonphysical abuse for females (47.6\%) and males (40.7\%).

\section{Bivariate analysis}

In the bivariate analysis, for females, any dating violence victimization was associated with depressive symptoms (feeling down/hopeless, having little interest in doing things), disordered eating (taking diet aids, fasting, vomiting), smoking daily for $30+$ days, and frequent sexual behavior (vaginal intercourse with $5+$ partners, oral sex with $5+$ partners, and anal sex with $1+$ partner) (Table 4). For males, any dating violence victimization was associated with depressive symptoms (feeling down/ hopeless), taking diet aids, and smoking daily for $30+$ days.

\section{Multivariable analysis}

There were few differences between the unadjusted models and the models adjusted for age and other abuse victimization (bullying; punched, kicked, choked by a parent/guardian; touched in a sexual place, forced to touch someone sexually). We report the results from the adjusted models (Table 5).

For females, more pronounced adverse health was observed for those exposed to physical/sexual versus nonphysical dating violence victimization. In analyses adjusted for age and non-dating abuse victimization (see definitions in Table 2), compared to non-exposed females, females with physical/sexual dating violence victimization were at increased risk of smoking for $30+$ days $(P R=3.95)$; depressive symptoms (feeling down/hopeless, $\mathrm{PR}=2.00$; lost interest in activities, $\mathrm{PR}=1.79$ ); eating disorders (taking diet aids, $\mathrm{PR}=1.98$; fasting, $\mathrm{PR}=4.71$; vomiting, $\mathrm{PR}=4.33$ ); and frequent sexual behavior (having $5+$ vaginal intercourse partners, $\mathrm{PR}=2.49$; having $5+$ oral sex

Table 3 Prevalence of dating violence victimization

\begin{tabular}{|c|c|c|c|c|c|c|}
\hline & \multicolumn{3}{|c|}{ Female $(\mathrm{N}=445)$} & \multicolumn{3}{|c|}{ Male $(\mathrm{N}=140)$} \\
\hline & \# Reporting abuse & Prevalence $(95 \% \mathrm{Cl})$ & RSE† & \# Reporting abuse & Prevalence $(95 \% \mathrm{Cl})$ & RSE† \\
\hline \multicolumn{7}{|l|}{ Physical/sexual } \\
\hline Physical & 25 & $5.6(3.5,7.8)$ & 19.4 & 17 & $12.1(6.7,17.6)$ & 22.8 \\
\hline Sexual - verbal coercion & 112 & $25.3(21.2,29.3)$ & 8.3 & 13 & $9.4^{*}(4.5,14.2)$ & 26.5 \\
\hline Sexual - physical force & 24 & $5.4(3.3,7.5)$ & 19.9 & 1 & $0.7^{*}(0.0,2.1)$ & 100 \\
\hline Any physical/sexual & 126 & $28.4(24.2,32.6)$ & 7.8 & 27 & $19.3(12.7,25.9)$ & 17.7 \\
\hline \multicolumn{7}{|l|}{ Non-physical } \\
\hline Threaten & 53 & $12.0(9.0,15.0)$ & 13.0 & 14 & $10.1^{*}(5.0,15.1)$ & 25.4 \\
\hline Controlling behavior & 124 & $27.9(23.7,32.1)$ & 7.7 & 29 & $20.7(14.0,27.5)$ & 16.5 \\
\hline Put down, name calling & 152 & $34.3(29.9,38.7)$ & 6.7 & 25 & $17.9(11.5,24.2)$ & 18.6 \\
\hline Yell, swore, insulted & 211 & $47.6(43.0,52.3)$ & 5.0 & 57 & $40.7(32.5,48.9)$ & 10.1 \\
\hline Unwanted calls, texts, visits & 128 & $28.9(24.7,33.1)$ & 7.6 & 36 & $25.7(18.4,64.7)$ & 14.3 \\
\hline Any non-physical & 287 & $64.6(60.2,69.1)$ & 3.6 & 79 & $56.4(48.2,64.7)$ & 7.4 \\
\hline Any TDV & 300 & $67.4(63.0,71.8)$ & 3.3 & 80 & $57.1(48.9,65.4)$ & 7.3 \\
\hline
\end{tabular}

† RSE = Relative Standard Error (standard error divided by the mean, expressed as a percentage).

*This estimate should be used with caution. Estimates with RSE $>25 \%$ are considered unreliable. 
Table 4 Bivariate associations between health indicators and any dating violence victimization

\begin{tabular}{|c|c|c|c|c|c|c|}
\hline & & Female & & & Male & \\
\hline & No TDV & Any TDV & p- & No TDV & Any TDV & p- \\
\hline & $N=145$ & $N=300$ & & $\mathrm{~N}=60$ & $\mathrm{~N}=80$ & \\
\hline Ever smoked & & & & & & \\
\hline No & 141 (97.2) & $265(88.3)$ & 0.002 & $57(95.0)$ & 67 (83.8) & 0.038 \\
\hline Yes & $4(2.8)$ & $35(11.7)$ & & $3(5.0)$ & $13(16.3)$ & \\
\hline $5+$ drinks on 6 & & & & & & \\
\hline No & $127(87.6)$ & $249(83.0)$ & 0.21 & $49(81.7)$ & $60(75.0)$ & 0.35 \\
\hline Yes & $18(12.4)$ & $51(17.0)$ & & $11(18.3)$ & $20(25.0)$ & \\
\hline Depression ( & & & & & & \\
\hline Have little inte & & & & & & \\
\hline No & $95(65.5)$ & $137(45.7)$ & $<0.001$ & $39(65.0)$ & $44(55.0)$ & 0.23 \\
\hline Yes & $50(34.5)$ & $163(54.3)$ & & $21(35.0)$ & $36(45.0)$ & \\
\hline Feel down, ho & & & & & & \\
\hline No & $107(73.8)$ & $166(55.3)$ & $<0.001$ & $46(76.7)$ & 47 (58.8) & 0.026 \\
\hline Yes & $38(26.2)$ & $134(44.7)$ & & $14(23.3)$ & $33(41.2)$ & \\
\hline Disordered e & & & & & & \\
\hline Fasted $24+$ ho & & & & & & \\
\hline No & $138(95.2)$ & 238 (79.3) & $<0.001$ & $57(95.0)$ & 71 (88.8) & 0.19 \\
\hline Yes & $7(4.8)$ & $62(20.7)$ & & $3(5.0)$ & $9(11.3)$ & \\
\hline Taken diet aid & & & & & & \\
\hline No & $126(86.9)$ & $231(77.3)$ & 0.016 & $57(95.0)$ & 67 (83.8) & 0.038 \\
\hline Yes & 19 (13.1) & $68(22.7)$ & & $3(5.0)$ & $13(16.2)$ & \\
\hline Vomited to lo & & & & & & \\
\hline No & 139 (95.9) & $258(86.3)$ & 0.002 & $60(100.0)$ & 76 (95.0) & 0.08 \\
\hline Yes & $6(4.1)$ & $41(13.7)$ & & $0(0.0)$ & $4(5.0)$ & \\
\hline Number of se & & & & & & \\
\hline Intercourse & & & & & & \\
\hline$<5$ & $128(89.5)$ & $219(75.0)$ & $<0.001$ & $52(91.2)$ & 66 (83.5) & 0.19 \\
\hline 5 or more & $15(10.5)$ & $73(25.0)$ & & $5(8.8)$ & $13(16.5)$ & \\
\hline Oral sex & & & & & & \\
\hline$<5$ & $124(86.7)$ & $224(76.5)$ & 0.012 & $50(86.2)$ & 65 (81.3) & 0.44 \\
\hline 5 or more & 19 (13.3) & 69 (23.6) & & $8(13.8)$ & 15 (18.8) & \\
\hline Anal sex & & & & & & \\
\hline None & $133(92.4)$ & $241(80.9)$ & 0.002 & 53 (89.8) & 66 (83.5) & 0.29 \\
\hline 1 or more & $11(7.6)$ & $57(19.1)$ & & $6(10.2)$ & $13(16.5)$ & \\
\hline
\end{tabular}

TDV = Teen dating violence.

partners, $\mathrm{PR}=2.02$; having anal sex, $\mathrm{PR}=2.82$ ). Compared to non-exposed females, females with non-physical dating violence only were at increased risk of smoking for $30+$ days $(\mathrm{PR}=3.61)$, depressive symptoms (feeling down/ hopeless, $\mathrm{PR}=1.41$; lost interest in activities, $\mathrm{PR}=1.36$ ), eating disorders (fasting, $\mathrm{PR}=3.37$; vomiting, $\mathrm{PR}=2.66$ ), having $5+$ intercourse partners $(P R=2.20)$, and having anal sex $(\mathrm{PR}=2.18)$.
In contrast, for males, no health differences were observed for those experiencing physical/sexual dating violence victimization compared to those who did not experience physical/sexual dating violence. Compared to non-exposed males, males with non-physical dating violence only were at increased risk of smoking $(\mathrm{PR}=3.91)$ and disordered eating (fasting, taking diet aids, vomiting, $\mathrm{PR}=2.93$ ). 
Table 5 Multivariable associations between health indicators and dating violence types (physical/sexual and non-physical only $)^{ \pm}$

\begin{tabular}{|c|c|c|c|c|c|}
\hline \multicolumn{6}{|c|}{ Among female respondents } \\
\hline & No TDV & Physical and/or sexual & Non-physical only & $\begin{array}{c}\text { Physical/sexual vs. } \\
\text { No TDV }\end{array}$ & $\begin{array}{c}\text { Non-physical only vs. } \\
\text { No TDV }\end{array}$ \\
\hline & $N=145$ & $N=126$ & $N=174$ & & \\
\hline & n (\%) & n (\%) & n (\%) & PR $(95 \% \mathrm{Cl})$ & PR $(95 \% \mathrm{Cl})$ \\
\hline Ever smoked daily for $30+$ days & $4(2.8)$ & $17(13.5)$ & $18(10.3)$ & $3.95(1.38,11.3)$ & $3.61(1.25,10.5)$ \\
\hline $5+$ drinks on 6 or more days in past 30 & $18(12.4)$ & $18(14.3)$ & $33(19.0)$ & $1.05(0.57,1.96)$ & $1.51(0.89,2.56)$ \\
\hline \multicolumn{6}{|l|}{ Depression (past 2 weeks) } \\
\hline Have little interest in doing things & $50(34.5)$ & $81(64.3)$ & $82(47.1)$ & $1.79(1.37,2.34)$ & $1.36(1.03,1.79)$ \\
\hline Feel down, hopeless & $38(26.2)$ & $69(54.8)$ & $65(37.4)$ & $2.00(1.45,2.76)$ & $1.41(1.01,1.97)$ \\
\hline \multicolumn{6}{|l|}{ Disordered eating (ever) } \\
\hline Fasted $24+$ hours to lose weight & $7(4.8)$ & $33(26.2)$ & $29(16.7)$ & $4.71(2.12,10.5)$ & $3.37(1.53,7.45)$ \\
\hline Taken diet aids to lose weight & $19(13.1)$ & $32(25.6)$ & $36(20.7)$ & $1.98(1.17,3.36)$ & $1.59(0.96,2.65)$ \\
\hline Vomited to lose weight & $6(4.1)$ & $22(17.6)$ & $19(10.9)$ & $4.33(1.72,10.9)$ & $2.66(1.09,6.51)$ \\
\hline \multicolumn{6}{|l|}{ Number of sexual partners } \\
\hline Intercourse (5 or more) & $15(10.5)$ & $34(27.4)$ & $39(23.2)$ & $2.49(1.43,4.32)$ & $2.20(1.27,3.80)$ \\
\hline Oral sex (5 or more) & 19 (13.3) & $35(28.2)$ & $34(20.1)$ & $2.02(1.22,3.33)$ & $1.53(0.92,2.54)$ \\
\hline Anal sex (1 or more) & $11(7.6)$ & $28(22.6)$ & $29(16.7)$ & $2.82(1.46,5.45)$ & $2.18(1.15,4.13)$ \\
\hline \multicolumn{6}{|c|}{ Among male respondents } \\
\hline & No TDV & Physical and/or sexual & Non-physical only & $\begin{array}{c}\text { Physical/sexual vs. } \\
\text { No TDV }\end{array}$ & $\begin{array}{c}\text { Non-physical only vs. } \\
\text { No TDV }\end{array}$ \\
\hline & $N=60$ & $N=27$ & $N=53$ & & \\
\hline & n (\%) & n (\%) & n (\%) & PR $(95 \% \mathrm{Cl})$ & PR $(95 \% \mathrm{Cl})$ \\
\hline Ever smoked daily for $30+$ days & $3(5.0)$ & $3(11.1)$ & $10(18.9)$ & $2.28(0.50,10.3)$ & $3.91(1.18,13.0)$ \\
\hline $5+$ drinks on 6 or more days in past 30 & $11(18.3)$ & $9(33.3)$ & $11(20.8)$ & $1.94(0.92,4.07)$ & $1.18(0.71,2.46)$ \\
\hline \multicolumn{6}{|l|}{ Depression (past 2 weeks) } \\
\hline Have little interest in doing things & $21(35.0)$ & $9(33.3)$ & $27(50.9)$ & $0.94(0.50,1.78)$ & $1.43(0.93,2.20)$ \\
\hline Feel down, hopeless & $14(23.3)$ & $11(40.7)$ & $22(41.5)$ & $1.68(0.88,3.23)$ & $1.69(0.98,2.92)$ \\
\hline Disordered eating (ever)* & $6(10.0)$ & $3(11.1)$ & $16(30.2)$ & $1.08(0.29,4.02)$ & $2.93(1.24,6.95)$ \\
\hline \multicolumn{6}{|l|}{ Number of sexual partners } \\
\hline Intercourse (5 or more) & $5(8.8)$ & $4(14.8)$ & $9(17.3)$ & $1.78(0.52,6.09)$ & $2.09(0.75,5.81)$ \\
\hline Oral sex (5 or more) & $8(13.8)$ & $6(22.2)$ & $9(17.0)$ & $1.52(0.60,3.82)$ & $1.14(0.47,2.73)$ \\
\hline Anal sex (1 or more) & $6(10.2)$ & $3(11.1)$ & $10(19.2)$ & $1.10(0.29,4.15)$ & $1.90(0.73,4.96)$ \\
\hline
\end{tabular}

TDV $=$ Teen dating violence.

$\mathrm{PR}=$ Prevalence ratio.

$\mathrm{Cl}=$ Confidence interval.

* Fasted 24+ hours, taken diet aids, or vomited to lose weight; these categories were combined for males due to the small sample size.

\pm Analysis adjusted for age, and prior abuse [bullying victimization, physical and sexual (non-dating) abuse victimization before age 18 , including being punched, kicked, choked, or receiving a more serious physical punishment from a parent or other adult guardian before age 18 (1 question) and being touched in a sexual place or being forced to touch another person when they did not want to before age 18 (1 question)].

\section{Discussion}

Compared to non-exposed females, females who experienced physical/sexual dating violence victimization from age 13 to 19 were at increased risk of depressive symptoms, disordered eating (taking diet aids, fasting, vomiting), smoking, and frequent sexual behavior (having 5+ vaginal intercourse and oral sex partners, having anal sex) in late adolescence. Compared to non- exposed subjects, females and males who experienced non-physical dating violence only were at increased risk of smoking in late adolescence; in addition, exposed males were at increased risk of disordered eating and females were at increased risk of depressive symptoms, disordered eating, having 5+ vaginal intercourse partners, and having anal sex. Our study findings are consistent with Exner-Cortens' recent longitudinal study 
noting more pronounced health impacts in late adolescence/young adulthood among females who had some experience of physical violence victimization [16]. Namely, the Exner-Cortens' study showed that females with physical violence victimization had increased risk of depressive symptoms, suicidal ideation, smoking, and adult violence victimization [16]. However, males in the Exner-Cortens' study seemed more adversely impacted by the experience of psychological abuse only, namely, they were at risk for antisocial behaviors, suicidal ideation, marijuana use, and adult violence victimization. Our study and that of Exner-Cortens were both limited in that they were not able to determine the qualitative nature of the dating violence acts assessed.

Our findings for females are also consistent with findings from other studies showing associations between physical/sexual dating violence victimization and adolescent depression [3]; disordered eating [8]; and having multiple sex partners [14]. Silverman and colleagues (2001) found strong associations between physical and/ or sexual violence victimization and laxative use (odds ratio $=3.2)$ and vomiting $(\mathrm{OR}=3.7)$ among adolescent females [8]; likewise, in our study, females who were physically and/or sexually abused by a dating partner had increased risk of using diet aids (prevalence ratio $=1.98$ ), vomiting $(\mathrm{PR}=4.31)$, and fasting $24+$ hours $(\mathrm{PR}=4.71)$. Silverman (2004) also found significant associations between the experience of physical/sexual dating violence victimization and having three or more sexual partners in the last three months [14]; this is consistent with our finding that females exposed to physical/sexual dating violence victimization were at increased risk of having multiple intercourse and oral sex partners.

Our findings for females are also consistent with Holt and Espelage's (2005) finding that adolescents exposed to non-physical dating violence are at increased risk of depression [15]. Females in our study who experienced non-physical dating violence only were at increased risk of feeling down/hopeless (prevalence ratio $=1.41$ ) and having little interest in doing things $(P R=1.36)$ compared to non-exposed females. In addition, females and males in our sample who were exposed to non-physical dating violence only (in the absence of physical/sexual violence) were at increased risk of smoking, males were at increased risk of disordered eating (combined category of fasting, using diet aids, vomiting), and females were at increased risk of fasting, vomiting, having 5+ vaginal intercourse partners, and having anal sex; these findings add to the literature on the health impact of non-physical dating violence, including Exner-Cortens' recent longitudinal study [16].

Prior studies of males have shown that the experience of physical and/or sexual dating violence is associated with increased risk of disordered eating [4,5]; post-traumatic stress symptoms, anxiety, and depression [4-6]; suicidal ideation and attempts [4,5]; smoking, alcohol and drug use [4,5]; and diminished emotional well-being [11]. Our findings for males did not support findings from prior studies; we found no significant associations between the experience of physical/sexual dating violence victimization and the health indicators measured in our study. The sample size for males in our study was small, which reduced statistical power. As well, differences in the way constructs were operationalized across studies could potentially account for differences in findings.

Our study had limitations. First, generalizability is compromised due to our sample of predominantly White subjects enrolled at a large Midwestern university. While the racial/ethnic distribution of our sample mirrors that of the university (http://undergrad.osu.edu/admissions/ quick-facts.html), our sample is less diverse than that of the U.S. population [77]. Second, males in our sample were under-represented; the small sample of males resulted in wide confidence intervals and reduced precision of the point estimates. With the reduced precision of the point estimates, the results for males should be interpreted with caution; with this said, our findings showing increased risk of disordered eating among dating violence-exposed males is consistent with the findings of prior studies [4,5]. Third, our first sample drawn from university registrar records had a response rate of $46.7 \%$; we did not have information on nonresponders to assess potential response bias. While our response rate of $46.7 \%$ may appear low, it is higher than other surveys of randomly-sampled adolescents (33\%) [78]. In a meta-analysis, Cook and colleagues (2000) determined that the mean response rate for mostly paper surveys across 49 studies was 39.6\% [79]. In a more recent meta-analysis comparing web- versus mail-survey modes, Shih and Fan (2008) reported that web survey modes generally have lower response rates (about 10\% lower) than mail surveys [80]. Fourth, even with our detailed retrospective dating violence assessment approach and with our validation analyses of the dating violence questions $[64,65]$, it is possible that subjects misestimated dating violence experiences [58]. This said, within the abuse assessment literature, variations in reporting are expected depending on how and when abuse is assessed [81-83]. In Jouriles' study, differential abuse reporting was observed by differing recall periods, with subjects reporting higher rates of abuse in an ongoing reporting versus a retrospective reporting approach [59]. This suggests that as time passes, subjects may be less likely to report and/or remember abuse. If the same trends were to hold in our study which used a retrospective assessment approach, it is possible that some "exposed" teens were included in the "non-exposed" group, which would dilute our study findings. Fifth, 
because our survey was cross-sectional; it was not possible to assess temporality (directionality between violence and health). Moreover, the small sample size precluded a specific examination of health impacts by the timing of abuse (middle- versus late- adolescence), as we have done in our larger studies of adults [24,26,55]; future studies should examine these issues. Finally, there could be unmeasured confounding in our study; in our multivariable analyses, we controlled for other potentially traumatic exposures such as bullying and non-dating abuse suffered before age 18 , but were unable in our survey to assess the full range of factors (e.g., parental substance abuse) that could introduce confounding.

Traumatic experiences during childhood adversely affect health in adulthood [58,72,73,84-89]. ExnerCortens' recent study showed that impaired health also results in adulthood from abuse experienced in adolescent relationships [16]. As an extension of the study's limitations, we did not assess factors that could help explain pathways between dating violence and health. In the groundbreaking Adverse Childhood Experiences (ACE) studies, researchers suggest that the amplified health effects resulting from multiple adverse experiences in childhood, including violence, are due to the exposure of the brain to the stress response, which impairs brain structure and function $[88,89]$. We did not have information about factors, such as stress, that could fall in the pathway between dating violence and health. We are aware of studies currently under review that examine the impact of dating violence on stress responses; these studies will be helpful in the future for explaining pathways. Finally, our future work focuses on collecting qualitative information about adolescents' dating violence experiences, including events leading up the abuse, abuse as it unfolds, and the aftermath. Information from forthcoming studies on stress responses and the qualitative nature of dating violence will further add to our understanding of dating violence.

\section{Conclusions}

These limitations notwithstanding, our findings showed adverse health in adolescents exposed to physical/sexual and non-physical types of dating violence, particularly for victimized females. This highlights the need to implement programs, such as Safe Dates [61,90], to prevent dating violence and to intervene when it occurs.

\section{Abbreviations}

CDC: Centers for disease control and prevention; Cl: Confidence interval; OR: Odds ratio; PR: Prevalence ratio; TDV: Teen dating violence.

\section{Competing interest}

The authors declare they have no competing financial or non-financial interests.

\section{Authors' contributions}

AEB conceptualized the study and survey, oversaw data collection and analysis, and wrote the manuscript with co-authors' input. MA helped design the survey, conducted the data analysis, and critically reviewed the manuscript. JMN and CB helped conceptualize the study and survey, added to the statistical analysis, and critically reviewed the manuscript. FPR helped design the survey and critically reviewed the manuscript. All authors read and approved the final manuscript.

\section{Author details}

${ }^{1}$ Human Development and Family Science, The Ohio State University, Columbus, OH, USA. ${ }^{2}$ Human Development and Family Studies, Michigan State University, East Lansing, MI, USA. ${ }^{3}$ Group Health Research Institute, Seattle, WA, USA. ${ }^{4}$ College of Public Health, The Ohio State University, Columbus, OH, USA. ${ }^{5}$ School of Public Health and Community Medicine and Department of Pediatrics, University of Washington, Seattle, WA, USA.

${ }^{6}$ Seattle Children's Hospital, Seattle, WA, USA.

Received: 20 November 2012 Accepted: 16 July 2013

Published: 10 September 2013

\section{References}

1. Smith $\mathrm{PH}$, White JW, Holland L: A longitudinal perspective on dating violence among adolescent and college-age women. Am J Public Health 2003, 93:1104-1109.

2. Halpern $C T$, Spriggs AL, Martin SL, Kupper LL: Patterns of intimate partner violence victimization form adolescence to young adulthood in a nationally representative sample. J Adolescent Health 2009, 45(5):508-518.

3. Slashinski MJ, Coker AL, Davis KE: Physical aggression, forced sex, and stalking victimization by a dating partner: an analysis of the National Violence Against Women Survey. Violence Vict 2003, 18(6):595-617.

4. Ackard DM, Neumark-Sztainer D, Hannan P: Dating violence among a nationally representative sample of adolescent girls and boys: associations with behavioral and mental health. $J$ Gender Specific Med 2003, 6(3):39-48.

5. Ackard DM, Eisenberg ME, Neumark-Sztainer D: Long-term impact of adolescent dating violence on the behavioral and psychological health of male and female youth. J Pediatr 2007, 151(5):476-481.

6. Callahan MR, Tolman RM, Saunders DG: Adolescent dating violence victimization and psychological well-being. J Adolescent Res 2003, 18(6):664-681.

7. Coker AL, McKeown RE, Sanderson M, Davis KE, Valois RF, Huebner ES: Severe dating violence and quality of life among South Carolina high school students. Am J of Prev Med 2000, 19:220-227.

8. Silverman JG, Raj A, Mucci LA, Hathaway JE: Dating violence against adolescent girls and associated substance use, unhealthy weight control, sexual risk behavior, pregnancy, and suicidality. JAMA 2001, 286:572-579.

9. Olshen E, McVeigh $\mathrm{KH}$, Wunsch-Hitzig RA, Rickert VI: Dating violence, sexual assault, and suicide attempts among urban teenagers. Arch Pediatr Adolescent Med 2007, 161(6):539-545.

10. Margolin G, Ramos MC, Baucom BR, Bennett DC, Guran EL: Substance Use, Aggression Perpetration, and Victimization: Temporal Co-occurrence in College Males and Females. J Interpers Violence 2013, 28(14):2849-2872.

11. Ackard DM, Neumark-Sztainer D: Date violence and date rape among adolescents: Associations with disordered eating behaviors and psychological health. Child Abuse Negl 2002, 26:455-473.

12. Decker MR, Silverman JG, Raj A: Dating violence and sexually transmitted disease/HIV testing diagnosis among adolescent females. Pediatrics 2005, 116(2):272-276.

13. Wingood GM, DiClemente RJ, McCree DH, Harrington K, Davies SL: Dating violence and the sexual health of black adolescent females. Pediatrics 2001, 107:E72

14. Silverman JG, Raj A, Clements K: Dating violence and associated sexual risk and pregnancy among adolescent girls in the United States. Pediatrics 2004, 114(2):220-225.

15. Holt MK, Espelage DL: Social support as a moderator between dating violence victimization and depression/anxiety among african american and caucasian adolescents. Soc Psychol Rev 2005, 34(3):309-328.

16. Exner-Cortens D, Eckenrode J, Rothman E: Longitudinal associations between teen dating violence victimization and adverse health outcomes. Pediatrics 2013, 31:71-78. 
17. Spriggs AL, Halpern CT, Martin SL: Continuity of adolescent and early adult partner violence victimization: association with witnessing violent crime in adolescence. J Epidemiol Community Health 2009, 63(9):741-748

18. Saltzman LE, Fanslow $J \mathrm{~L}, \mathrm{McM}$ ahon $\mathrm{P}$, Shelley GA: Intimate partner violence surveillance: Uniform definitions and recommended data elements. Version 1.0. Atlanta: National Center for Injury Prevention and Control, Centers for Disease Control and Prevention; 1999.

19. Black MC, Basile KC, Breiding MJ, Smith SG, Walters ML, Merrick MT, Chen JT, Stevens MR: The National Intimate Partner and Sexual Violence Survey (NISVS): 2010 Summary Report. Atlanta: National Center for Injury Prevention and Control, Centers for Disease Control and Prevention; 2011.

20. Centers for Disease Control and Prevention: What is Dating Violence? [http://www.cdc.gov/violenceprevention/intimatepartnerviolence/ teen_dating_violence.html]. Accessed September 7, 2013.

21. Lyndon A, Bonds-Raacke J, Cratty AD: College students' facebook stalking of ex-partners. Cyberpsychology Behav Soc Netw 2011, 14(12):711-716.

22. Bonomi AE, Anderson ML, Nemeth J, Bartle-Haring S, Buettner C, Schipper D: Dating violence victimization across the teen years: abuse frequency, number of abusive partners, and age at first occurrence. BMC Public Health 2012, 12:637.

23. Coker AL, Davis KE, Arias I, Desai S, Sanderson M, Brandt HM, Smith PH: Physical and mental health effects of intimate partner violence for men and women. Am J Prev Med 2002, 23:260-268.

24. Bonomi AE, Thompson RS, Anderson ML, Reid RJ, Carrell D, Dimer JA, Rivara FP: Intimate partner violence and women's physical, mental, and social functioning. Am J Prev Med 2006, 30:458-466.

25. Bonomi AE, Anderson ML, Rivara FP, Thompson RS: Health outcomes in women with physical and/or sexual intimate partner violence exposure. J Womens Health 2007, 16(7):987-997.

26. Reid RJ, Bonomi AE, Rivara FP, Anderson ML, Fishman PA, Carrell DS, Thompson RS: Intimate partner violence among men prevalence, chronicity, and health effects. Am J Prev Med 2008, 34(6):478-485.

27. Peltzer K, Pengpid S, McFarlane J, Banyini M: Mental health consequences of intimate partner violence in Vhembe district, South Africa. General Hospital Psychiatry 2013, 2 [Epub ahead of print].

28. Dines G: Pornland: How Porn Has Hijacked Our Sexuality. Boston: Beacon; 2010

29. DeKeseredy WS, Olsson P: Adult pornography, male peer support, and violence against women: The contribution of the "dark side" of the internet. In Technology for Facilitating Humanity and Combating Social Deviations: Interdisciplinary Perspectives. Edited by Vargas Martin M, Garcia-Ruiz MA, Edwards A. Hershey, P.A: Information Science Reference; 2011:34-50.

30. Drouin $M$, Landgraff $C$ : Texting, sexting, and attachment in college students' romantic relationships. Comput Human Behav 2012, 28(2):444-449.

31. Weisskirch RS, Delevi R: "Sexting" and adult romantic attachment. Comput Human Behav 2011, 27(5):1697-1701.

32. Lin J-S, Pena J: Are you following me? a content analysis of TV net brand communication on Twitter. J Interactive Advertising 2011, 12(1):17-29.

33. Doring N, Dietmar C: Mediated communication in couple relationships: approaches for theoretical modeling and first qualitative findings. Qual Soc Res 2003, 4(3). http://www.qualitative-research.net/index.php/fqs/ article/view/676/1462. Accessed September 7, 2013.

34. Pujazon-Zazik M, Park MJ: To Tweet or not to Tweet: gender differences and potential positve and negative outcomes of adolescents' social internet use. Am J Mens Health 2010, 4(1):77-85.

35. Valkenburg PM, Peter J, Schouten AP: Friend networking sites and their relationship to adolescents' well-being and social self-esteem. Cyberpsychology Behav Soc Netw 2006, 9(5):584-590.

36. Fox J, Warber KM: Romantic relationship development in the age of Facebook: An exploratory study of emerging adults' perceptions, motives, and behaviors. Cyberpsychology Behav Soc Netw 2013, 16(1):3-7.

37. Valkenburg PM, Peter J: Online communication and adolescent well-being: testing the stimulation versus the displacement hypothesis. J Comput Mediated Communication 2007, 12(4):1169-1182.

38. Valkenburg PM, Peter J: Adolescents' identity experiments on the internet: consequences for socail competence and self-concept unity. Communication Res 2008, 35(2):208-231.
39. Peter J, Valkenburg PM: Adolescents' exposure to a sexualized media environment and their notions of women as sex objects. Sex Roles 2007 56(5-6):381-395

40. England P, Fitzgibbons Shafer E, Fogarty ACK: Hooking up and forming romantic relationships on today's college campuses. In The Gendered Society Reader. 3rd edition. Edited by Kimmel MS, Aaronson A. New York: Oxford University Press; 2008:531-547.

41. Kalish R, Kimmel MS: Hot hetero sex or the new numb normative? Australian Feminist Studies 2011, 26(67):137-151.

42. Young BJ, Furman W, Jones MC: Changes in adolescents' risk factors following peer sexual coercion: evidence for a feedback loop. Dev Psychopathol 2012, 24(2):559-571.

43. Brown AL, Testa M, Messman-Moore TL: Psychological consequences of sexual victimization resulting from force, incapacitation, and verbal coercion. Violence Against Women 2009, 15(8):898-919.

44. Fair CD, Vanyur J: Sexual coercion, verbal aggression, and condom use consistency among college students. J Am Coll Health 2011, 59(4):273-280

45. Spitzer RL, Kroenke K, Williams JB: Validation and utility of a self-report version of PRIME-MD: the PHQ primary care study. JAMA 1999, 282:1737-1744

46. Richardson LP, Rockhill C, Russo JE, Grossman D, Richards J, McCarty C, McCauley E, Katon W: Evaluation of the PHQ-2 as a brief screen for detecting major depression among adolescents. Pediatrics 2010, 125(5):1097-1103.

47. CDC: Youth Risk Behavior Surveillance - United States, 2009. MMWR 2010, 59(SS-5):1-142.

48. Tanney MR, Naar-King S, Murphy DA, Parsons JT, Janisse H: Multiple risk behaviors among youth living with human immunodeficiency virus in five U.S. cities. J Adolescent Health 2010, 46(1):11-16.

49. Evans SM, Levin FR, Brooks DJ, Garawi F: A pilot double-blind treatment trial of memantine for alcohol dependence. Alcohol Clin Exp Res 2007, 31(5):775-782

50. Sacks JA, Drake RE, Williams VF, Banks SM, Herrell JM: Utility of the time-line follow-back to assess substance use among homeless adolescents. J Nervous Mental Disorders 2003, 191(3):145-153.

51. Thompson RS, Bonomi AE, Anderson M, Reid RJ, Dimer JA, Carrell D, Rivara FP: Intimate partner violence: Prevalence, types, and chronicity in adult women. Am J Prev Med 2006, 30:447-457.

52. Bonomi AE, Anderson ML, Cannon EA, Slesnick N, Rodriguez MA: Prevalence and health associated with intimate partner violence in insured Hispanic and non-Hispanic women. Am J Prev Med 2009, 36(1):43-48.

53. Bonomi AE, Anderson ML, Reid RJ, Rivara FP, Carrell D, Thompson RS: Medical and psychosocial diagnoses in women with a history of intimate partner violence. Arch Intern Med 2009, 169(18):1692-1697.

54. Bonomi AE, Anderson ML, Rivara FP, Thompson RS: Health care utilization and costs associated with physical and non-physical intimate partner violence. Health Serv Res 2009, 44(3):1052-1067.

55. Rivara FP, Anderson ML, Fishman $\mathrm{P}$, Bonomi AE, Reid RJ, Carrell D, Thompson RS: Healthcare utilization and costs for women with a history of intimate partner violence. Am J Prev Med 2007, 32(2):89-96.

56. Rivara FP, Anderson ML, Fishman PA, Reid RJ, Bonomi AE, Carrell D, Thompson RS: Time period cohort effects of intimate partner violence. Violence Vict 2009, 24(5):627-638.

57. Rivara FP, Anderson ML, Fishman P, Bonomi AE, Reid RJ, Carrell D, Thompson RS: Intimate partner violence and health care costs and utilization for children living in the home. Pediatrics 2007, 120(6):1270-1277.

58. Widom CS, DuMont K, Czaja SJ: A prospective investigation of major depressive disorder and comorbidity in abused and neglected children grown up. Arch Gen Psychiatry 2007, 64(1):49-56

59. Jouriles EN, McDonald R, Garrido E, Rosenfield D, Brown AS: Assessing aggression in adolescent romantic relationships: Can we do it better? Psychol Assess 2005, 17:469-475.

60. Hickman LJ, Jaycox LH, Aronoff J: Dating violence among adolescents: Prevalence, gender distribution, and prevention program effectiveness. Trauma Violence Abuse 2004, 5:123-142.

61. Foshee VA, Linder GF, Bauman KE, Langwick SA, Arriaga XB, Heath JL, McMahon PM, Bangdiwala S: The Safe Dates Project: Theoretical basis, 
evaluation design, and selected baseline findings. Am J Prev Med 1996 12(5 Suppl):39-47.

62. Swahn $\mathrm{MH}$, Alemdar M, Whitaker DJ: Nonreciprocal and reciprocal dating violence and injury occurrence among urban youth. Western J Emergency Med 2010, 11(3):264-268

63. Swahn MH, Simon TR, Arias I, Bossarte RM: Measuring sex differences in violence victimization and perpetration within date and same-sex peer relationships. J Interpers Violence 2008, 23:1120-1138.

64. Nemeth J, Bonomi AE, Lomax R: Initial validation of the Retrospective Teen Dating Violence Assessment (RTVDA). Washington, DC: Women's Health Congress; 2013.

65. Nemeth JM, Bonomi $A E$, Lomax R: Initial validation of the retrospective teen dating violence assessment (RTDVA). Journal of Women's Health 2013, 22(3):1-48. P.90.

66. Coker AL, Smith PH, Bethea L, King MR, McKeown RE: Physical health consequences of physical and psychological intimate partner violence. Arch Fam Med 2000, 9:451-457.

67. Coker AL, Pope BO, Smith PH, Sanderson M, Hussey JR: Assessment of clinical partner violence screening tools. J Am Med Womens Assoc 2001, 56:19-23.

68. CDC: Physical dating violence among high school students - United States, 2003. MMWR 2006, 55(19):532-535.

69. Zou G: A modified poisson regression approach to prospective studies with binary data. Am J Epidemiol 2004, 159:702-706.

70. Arnow BA, Hart S, Scott C, Dea R, O'Connell L, Taylor CB: Childhood sexual abuse, psychological distress, and medical use among women. Psychosom Med 1999, 61(6):762-770.

71. Arnow BA, Hart S, Hayward C, Dea R, Taylor CB: Severity of child maltreatment, pain complaints and medical utilization among women. J Psychiatr Res 2000, 34(6):413-421.

72. Bonomi AE, Anderson ML, Rivara FP, Cannon EA, Fishman PA, Carrell D, Reid RJ, Thompson RS: Health care utilization and costs associated with child abuse. J Gen Intern Med 2008, 23(3):294-299.

73. Bonomi AE, Cannon EA, Anderson ML, Rivara FP, Thompson RS: Association between self-reported health and physical and/or sexual abuse experienced before age 18. Child Abuse Negl 2008, 32(7):693-701.

74. Chartier MJ, Walker JR, Naimark B: Childhood abuse, adult health, and health care utilization: results from a representative community sample. Am J Epidemiol 2007, 165(9):1031-1038.

75. Gruber JE, Fineran S: Comparing the impact of bullying and sexual harrassment victimization on the mental and physical health of adolescents. Sex Roles 2008, 59(1-2):1-13.

76. StataCorp: Stata Statistical Software: Release 12. College Station, TX: StataCorp LP; 2011.

77. American Community Survey. [http://factfinder.census.gov/servlet/ ADPGeoSearchByListServlet?ds_name=ACS_2005_EST_G00_\&_lang=en\&_ ts $=197804625156$.

78. Richards J, Wiese C, Katon W, Rockhill C, McCartey C, Grossman D, McCauley E, Richardson LP: Surveying adolescents enrolled in a regional health care delivery organization: mail and phone follow-up-what works and at what cost? J Am Board Fam Med 2010, 23(4):534-541.

79. Cook CS, Heath F, Thompson RL: A meta-analysis of response rates in web- or internet-based surveys. Educ Psychol Meas 2000, 60:821-836.

80. Shih $\mathrm{T}$, Fan $\mathrm{X}$ : Comparing response rates from web and mail surveys: a meta-analysis. Field Methods 2008, 20(3):249-271.

81. Bonomi AE, Holt VL, Thompson RS, Martin D: Ascertainment of intimate partner violence in women seeking legal protection. Am J Prev Med 2005, 28:52-58.

82. Bonomi AE, Thompson RS, Anderson M, Rivara FP, Holt VL, Carrell D, Martin DP: Ascertainment of intimate partner violence using two abuse measurement frameworks. Inj Prev 2006, 12:121-124.

83. Bonomi AE, Allen DG, Holt VL: Conversational silence, coercion, equality: The role of language in influencing who gets identified as abused. Soc Sci Med 2006, 62:2258-2266.

84. Edwards VJ, Holden GW, Felitti VJ, Anda RF: Relationship between multiple forms of childhood maltreatment and adult mental health in community respondents: results from the adverse childhood experiences study. Am J Psychiatry 2003, 160(8):1453-1460.

85. Corso PS, Edwards VJ, Fang X, Mercy JA: Health-related quality of life among adults who experienced maltreatment during childhood. Am J Public Health 2008, 98(6):1094-1100.
86. Walker EA, Gelfand A, Katon WJ, Koss MP, Von Korff M, Bernstein D, Russo J: Adult health status of women with histories of childhood abuse and neglect. Am J Med 1999, 107(4):332-339.

87. Walker EA, Unutzer J, Rutter C, Gelfand A, Saunders K, VonKorff M, Koss MP, Katon W: Costs of health care use by women HMO members with a history of childhood abuse and neglect. Arch Gen Psychiatry 1999. 56(7):609-613.

88. Anda RF, Felitti VJ, Bremner JD, Walker JD, Whitfield C, Perry BD, Dube SR, Giles $W H$ : The enduring effects of abuse and related adverse experiences in childhood. A convergence of evidence from neurobiology and epidemiology. Eur Arch Psychiatry Clin Neurosci 2006, 256(3):174-186.

89. Anda RF, Croft JB, Felitti VJ, Nordenberg D, Giles WH, Williamson DF, Giovino GA: Adverse childhood experiences and smoking during adolescence and adulthood. JAMA 1999, 282(17):1652-1658.

90. Foshee VA, Bauman KE, Ennett ST, Linder GF, Benefield T, Suchindran C: Assessing the long-term effects of the safe dates program and a booster in preventing and reducing adolescent dating violence victimization and perpetration. Am J Public Health 2004, 94:619-624.

doi:10.1186/1471-2458-13-821

Cite this article as: Bonomi et al:: History of dating violence and the association with late adolescent health. BMC Public Health 2013 13:821.

\section{Submit your next manuscript to BioMed Central and take full advantage of:}

- Convenient online submission

- Thorough peer review

- No space constraints or color figure charges

- Immediate publication on acceptance

- Inclusion in PubMed, CAS, Scopus and Google Scholar

- Research which is freely available for redistribution

Submit your manuscript at www.biomedcentral.com/submit
C) Biomed Central 